\title{
The Effectiveness of Go Green Implementation among Society in Kota Bharu, Kelantan
}

\author{
Che Rusuli M.S., Naqiah M. \\ Fitriani Q, Syahida N. \\ Hakim M. \\ Faculty of Entrepreneurship and Business \\ Universiti Malaysia Kelantan Kampus Kota, \\ Pengkalan Chepa, 16100 Kota Bharu, Kelantan. \\ Corresponding email: msaufi@umk.edu.my
}

\begin{abstract}
Nowadays, Go Green has becoming an initiative in protecting the natural resources for the next generation and protects human health through environmental management and implementation of green ways of life. This study seeks to identify the effectiveness of the implementation of Go Green by Majlis Perbandaran Kota Bharu (MPKB) Kelantan. The population of this study includes society in Kelantan and 200 respondents will be involved which is lives in Pengkalan Chepa, Kubang Kerian, Pasir Tumboh, Wakaf Bharu and Kijang. The results from this study hoped will contribute to the body of knowledge which has a positive significant relationship with education, technologies and legal actions.
\end{abstract}

Keywords: Environmental management, Green, Education, Technologies, Legal actions.

\section{Introduction}

The awareness towards having healthy life is increasing day by day. Go green campaigns are widely used to expose the environmental issues to the public and at the same time to inculcate the awareness of green behavior on the environment. Go Green campaigns becoming very important to keep our environment clean and healthy from any disease as well as free pollutions. Latest news reported that the severe haze with a high API that caused by an open burning claimed many lives of the society and this situation should be taken into action in order to overcome it. Many parties (e.g. government, state, local authority, etc.) have to take this matter seriously and each person in this world has to know the important of Go Green implementation so that they able to protect our planet from destroyed. For example, pollution can happen from various types such as air, water, soil, noise, radioactive, thermal, light and visual. Other than that, it could lead to killing diseases for instance long period of time disclosure to polluted air can give effects to loss of lung capacity, decreased the lung function and could shortened life span. On the other hand, water pollution may possibly cause diarrhea, malaria, hepatitis $\mathrm{A}$, lead poisoning and many more which can be conclude that different type of pollution are able to lead to different type of diseases that possibly will take someone life especially the lives of your loves ones. All these can happen when there is no action have been taken to implement Go Green in people daily lives. Although, there are global campaign have taken place such as Earth Hour, Earth Day, World Environment Day and so on, but it still not effective if no one is practicing and implementing Go Green approach in their daily lives. Moreover, people or society need to change their habit (e.g. throwing rubbish in public, use recycle items and reduce the usage of plastics bag) in order to reduce global warming.

A large number of customers show increased environmental awareness and a preference for green concept (e.g.: firms, products, etc.), revealing their willingness to purchase and pay more (Han et al., 2011). Consumers or individual who are well aware and concerned about the environmental issues are known as green consumers (Soonthonsmai, 2007). At present, people have aware that their consumption activities will lead to the environmental problems (Tsen et al., 2006). Carrus et al. (2015) state that social interaction in natural environments may represent a source of distraction from the relationship with restorative natural environments. It is found by Murray (2012) that if rebound effects are ignored when evaluating 'green' consumption, environmental benefits will be overstated by around $20 \%$ for reduced vehicle use, and $7 \%$ 
for reduced electricity use. Commonly, in business world or manufacturing industry have done many effort on producing the products in green standards. People also need to aware how important green product in their live, even they not perfectly implementing go green in their daily life. The term "green" usually connecting on keep the environment clean and it refers to the action that reduce the impact on the environment and keep it clean or free from any pollution such as reuse the certain item, recycling or purchasing green product (Wolfe \& Shanklin, 2001).

According to Coleman (2011), Go Green consumption can have different meanings for different people and different purposes. Thus, this study defined "Go Green" is the initiative in protecting the natural resources for our next generation and protects human health through environmental management and implementing green ways of life. Higher education must play important roles to educate the next generation, not only to promote social and economic development, but they should ensure these developments will be sustainable (Xiong et al., 2013). Until now, only several countries has implement Green concept in their daily life and it was not successful educate. Building "green curricula" is the most crucial part to increase students' environmental awareness in school and university (Boks \& Diehl, 2006). Nejati and Nejati (2013) urged that universities worldwide are changing their mission, vision, and educational practices to better cope with growing concerns about social and environmental issues. Still many of university especially leaders and academicians are unaware or ignorant of sustainability principles in the university setting. Many of the activities related to green in the university has remained unsustainable (Lim et al., 2015; Geng et al., 2013; Xiong et al., 2013; Lozano, 2006).

Knowledge is recognized in consumer research as a characteristic that influences all phases in the decision process (Laroche et al., 2001). Knowledge and information about Go Green had been publicly spread. However, there are slow effort to develop the culture on practicing in daily life such as campaign, talk, program and etc. Geng et al. (2013) noted that pamphlets and outdoor bulletin boards that contain best practices of green need to be daily promote to the society. Hosseinpour et al. (2015) revealed a previous studies done by Han et al. (2009) and Laroche et al. (2001) observed that women have strongly different in terms of having environmentally friendly behavior rather than men. These studies concluded that not only women are more environmentally concerned but they also willing to pay for green products. Nejati and Nejati (2013) found that this Go Green issues remains under researched and needs to be further explored.

Nevertheless, those efforts (Coleman et al., 2011; Tsen et al., 2006; Wolfe \& Shanklin, 2001) still inadequate and not give much impact or affect towards society. Furthermore, this study seeks to know how effective the implementation of Go Green among society in Kota Bharu, Kelantan especially Majlis Perbadanan Kota Bharu (MPKB) management. The objectives of this study are as follows:

R01. To identify the level of education that influences the implementation of Go Green in MPKB.

RO2. To determine the level of awareness, education and knowledge attitudes towards Go Green implementation in MPKB.

RO3. To recommend solution to MPKB towards implementation of GO GREEN activities.

The present study attempts to answer the following four principal research questions are formulated:

RQ1. Is it the level of education influence GO GREEN implementation?

$\mathrm{RQ2}$. Is there any significant relationship between level of awareness, education and knowledge attitude towards Go Green implementation?

RQ3. Is there any recommendation or solution towards Go Green implementation activities to MPKB? 


\section{THEORETICAL FRAMEWORK}

The underpinned framework for this study was derived from the in-depth factors and theoretical statements from preceding works. The following model in Figure 1 illustrates the relationship between awareness attitudes, level of education and knowledge.

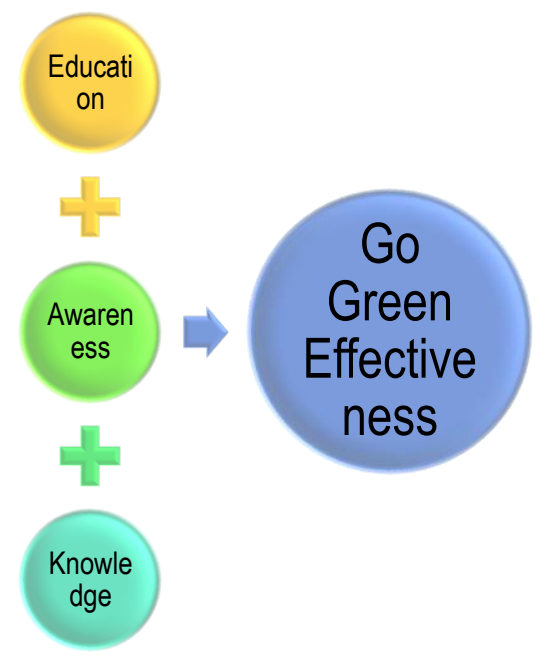

Figure 1. A Proposed of Go Green Theoretical Framework

\section{Methods}

Research methodology is refer to effective method to get the useful information with the minimum cost in achieve a research (Babbie, 2011; Bhattacherjee, 2012; Creswell, 2003; Fowler, 2009). To give the focus, this study will determine the suitable research methodology for applied to achieve the original purpose of the research. The population of this study is society that lives in Kelantan. The sample of the study is 300 respondents which live area of Pengkalan Chepa, Kubang Kerian, Pasir Tumboh, Wakaf Bharu and Kijang. Questionnaire will be use to be answered by respondent and return it within a certain period of time. The data was analyzed by using SPSS system. Descriptive statistics were used to analyze, organize, summarize and describe the collected data. This software can predict with confidence what will happen next so it can make smarter decisions, solve problems and improve outcomes.

\section{Expected Outcome}

Expected outcome is a prediction what the researcher expects after the study has conducted. These studies have three outcomes which are educations, technologies and legal actions. The first expected outcome is to provide more green education and awareness towards Go Green since primary school or kindergarten. It's explained details about effect, cost and benefit that they will get if all the society implementing Go Green activities. If they succeed, they will protect the environment all the time.

\section{Practical Implications}

The second expected outcomes is to create a machine so called "Recycle Go Green Vending Machine" that can accept recycle tin can and the others waste will be disposed. For the recycle waste such as bottle, paper, plastic and aluminums 
canned will be enter to the machines, and there will be exchange into coins. Furthermore, if this vending machine started to use in UMK, the machine could generate income back to university.

\section{Society Implications}

Lastly, the implementation of recycle law for environmental care needs to be tightened. At present, the society is not concerned to the environmental care that can be seen around Kota Bharu. Other countries around the world apply this recycle policy. For example, university or schools are the focus of sustainability efforts because they are both extremely important sites of learning and significant consumers of natural resources. Through the existing case study could help people to illustrate on how conservation efforts (directed at energy and resource use) can directly address environmental sustainability and support environmental education (Schelly et al., 2012.)

\section{Conclusion}

Of course, this research is limited by its very nature as a case study. While individual cases can offer rich descriptions, rich answer how and why questions, and provide propositions for new theory. The study also tends to propose more complex theories than can be validated by examination of a wider variety of cases. However, the limitation of the study has come across, but, our expected outcome is focuses on the development practicing Go Green in people daily life from the beginning of age. Future research should examine a wider such as variety of cases, degrees of conservation and types of sustainability efforts in order to develop theories and practices in the school level efforts that contribute to the Go Green practices.

\section{References}

Babbie, E. (2011). Introduction to social research (5th ed.): Belmont Wadsworth.

Bhattacherjee, A. (2012). Social Science Research: Principles, Methods, and Practices. Zurich, Switzerland: Global Text Project.

Boks, C., \& Diehl, J. C. (2006). Integration of sustainability in regular courses: experiences in industrial design engineering. Journal of Cleaner Production, 14(9), 932-939.

Carrus, G., Scopelliti, M., Lafortezza, R., Colangelo, G., Ferrini, F., Salbitano, F., . . Sanesi, G. (2015). Go greener, feel better? The positive effects of biodiversity on the well-being of individuals visiting urban and peri-urban green areas. Landscape and Urban Planning, 134, 221-228.

Coleman, L. J., Bahnan, N., Kelkar, M., \& Curry, N. (2011). Walking the walk: how the theory of reasoned action explains adult and student intentions to go green. Journal of Applied Business Research (JABR), 27(3), 107-116.

Creswell, J. W. (2003). Research design: Qualitative, quantitative, and mixed methods approaches. London: Sage Publications.

Fowler, F. J. (2009). Survey research methods (4th ed.). London: Sage Publications.

Geng, Y., Liu, K., Xue, B., \& Fujita, T. (2013). Creating a "green university" in China: a case of Shenyang University. Journal of Cleaner Production, 61, 13-19.

Han, H., Hsu, L.-T. J., Lee, J.-S., \& Sheu, C. (2011). Are lodging customers ready to go green? An examination of attitudes, demographics, and eco-friendly intentions. International Journal of Hospitality Management, 30(2), 345-355.

Laroche, M., Bergeron, J., \& Barbaro-Forleo, G. (2001). Targeting consumers who are willing to pay more for environmentally friendly products. Journal of consumer marketing, 18(6), 503-520.

Lim, Y. S., Xia, B., Skitmore, M., Gray, J., \& Bridge, A. (2015). Education for sustainability in construction management curricula. International Journal of Construction Management, 15(4), 321-331. 
Lozano, R. (2006). Incorporation and institutionalization of SD into universities: breaking through barriers to change. Journal of Cleaner Production, 14(9), 787-796.

Murray, C. K. (2013). What if consumers decided to all 'go green'? Environmental rebound effects from consumption decisions. Energy Policy, 54, 240-256.

Nejati, M., \& Nejati, M. (2013). Assessment of sustainable university factors from the perspective of university students. Journal of Cleaner Production, 48, 101-107.

Schelly, C., Cross, J. E., Franzen, W., Hall, P., \& Reeve, S. (2012). How to go green: creating a conservation culture in a public high school through education, modeling, and communication. The Journal of Environmental Education, 43(3), 143-161.

Soonthonsmai, V. (2007). Environmental or green marketing as global competitive edge: Concept, synthesis, and implication. Paper presented at the EABR (Business) and ETLC (Teaching) Conference Proceeding, Venice, Italy.

Tsen, C.-H., Phang, G., Hasan, H., \& Buncha, M. R. (2006). Going green: A study of consumers' willingness to pay for green products in Kota Kinabalu. International Journal of Business and Society, 7(2), 40-54.

Wolfe, K. L., \& Shanklin, C. W. (2001). Environmental practices and management concerns of conference center administrators. Journal of Hospitality \& Tourism Research, 25(2), 209-216.

Xiong, H., Fu, D., Duan, C., Chang'E, L., Yang, X., \& Wang, R. (2013). Current status of green curriculum in higher education of Mainland China. Journal of Cleaner Production, 61, 100-105. 